\title{
Economic burden of refractory chronic spontaneous urticaria on Kuwait's health system
}

This article was published in the following Dove Press journal:

ClinicoEconomics and Outcomes Research

10 May 2016

Number of times this article has been viewed

Mona Al-Ahmad'

Maryam S Alowayesh ${ }^{2}$

Norman V Carroll ${ }^{3}$

'Microbiology Department, Faculty of Medicine, ${ }^{2}$ Pharmacy Practice

Department, Faculty of Pharmacy, Kuwait University, Kuwait; ${ }^{3}$ Division of Pharmacoeconomics and Health Outcomes, School of Pharmacy, Virginia Commonwealth University, VA, USA

Correspondence: Mona Al-Ahmad Microbiology Department, Faculty of Medicine, Kuwait University, PO Box 24923, Safat I 3 | I 0, Kuwait Tel +96524636515

Fax+965 25332719

Email Alahmadm@hsc.edu.kw
Background: Chronic spontaneous urticaria (CSU) is a common problem worldwide. We evaluated the direct medical costs of treating patients with refractory CSU and the budget effect of omalizumab use in these patients in Kuwait.

Methods: The prevalence of CSU was estimated using the Delphi method. Medical records of patients with refractory CSU in Kuwait were reviewed. Costs were calculated from a health system perspective. One-way sensitivity analyses were conducted on the price and utilization of each cost component.

Results: Before omalizumab use, the total direct costs of treating 1,293 patients with refractory CSU were estimated to be USD 3,650,733 per year. This estimation was principally generated by outpatient visits. After omalizumab use, the cost was sensitive to price variation and estimated to be USD 15,828,612 per year. All other direct costs were reduced.

Conclusion: The economic burden of refractory CSU in Kuwait is high. Omalizumab use is costly, but its administration reduces all other direct costs.

Keywords: cost, chronic urticaria, Kuwait, omalizumab, economic, Middle East

\section{Introduction}

Chronic urticaria (CU) is a skin disorder characterized by the recurrent appearance of wheals and/or angioedema for $>6$ weeks. ${ }^{1} \mathrm{CU}$ is a heterogeneous disorder and includes chronic spontaneous urticaria (CSU) and chronic inducible urticaria (CIU). ${ }^{2}$ In most patients, the underlying cause of CSU, which is the most frequent form of CU, is not identified in clinical practice. Known underlying causes include autoimmunity, ie, the development of functional autoantibodies to the high-affinity immunoglobulin E (IgE) receptor (FceRI) or IgE, which induces the release of histamine and other mediators (including proteases, eicosanoids, and cytokines) from mast cells and basophils, as well as the development of wheals and angioedema. ${ }^{3}$ A group of patients with CSU who produce IgE against autoantigens, including thyroid peroxidase, has also been described. ${ }^{4}$ Patients with CSU with autoantibodies reportedly have more severe urticaria than patients without autoantibodies, and they may be more resistant to treatment. ${ }^{5,6}$

The worldwide prevalence of $\mathrm{CU}$ is estimated at $0.5 \%-1 \%{ }^{7}$ In the Middle East, few data are available on the epidemiology of the disease, and even fewer are available on the economic impact of CSU on the health system sector.

CSU is a debilitating disease that has a great influence on patients' quality of life $(\mathrm{QoL})^{7,8}$ and a huge impact on society through health care costs and a loss of working hours. $^{7,9-11}$ 
According to international guidelines, ${ }^{12}$ the first-line treatment for patients with CSU is second-generation (nonsedating) $\mathrm{H}_{1}$-antihistamines taken on a regular basis. If symptoms persist after 2 weeks, an increase of up to four times the normally prescribed dose of $\mathrm{H}_{1}$-antihistamines is advised. If symptoms persist despite higher doses of $\mathrm{H}_{1}$-antihistamines, the guidelines recommend the addition of cyclosporin, montelukast (a leukotriene antagonist), or omalizumab. ${ }^{12}$

Omalizumab (Xolair ${ }^{\mathrm{TM}}$; Novartis International AG, Basel, Switzerland/Genentech, Inc., South San Francisco, CA, USA) is a recombinant humanized anti-IgE monoclonal antibody. The US Food and Drug Administration (FDA) and the European Medicines Agency have recently approved omalizumab for the treatment of CSU. ${ }^{13-15}$ Omalizumab works by binding the $\mathrm{C} 3$ domain of the $\mathrm{IgE}$ heavy chain, where $\operatorname{IgE}$ binds to FCER1, and subsequently inhibits mast cell activation. ${ }^{16} \mathrm{In} \mathrm{CU}, \sim 50 \%$ of patients are refractory to the use of the maximum licensed doses of second-generation $\mathrm{H} 1$-antihistamines. Omalizumab has been shown to have a favorable risk/benefit ratio, and it is very well tolerated in clinical studies. ${ }^{14}$ Patients with CSU with persistent symptoms despite maximum treatment with antihistamines could benefit from add-on therapy with subcutaneous omalizumab at a dose of $300 \mathrm{mg}$ every 4 weeks, with significant reduction in the severity of itching, the number and size of hives, and increased health-related QoL. ${ }^{17-19}$

The overall objective of the study was to estimate the direct medical costs of CSU in patients who do not respond to standard therapy (antihistamine and/or corticosteroids) and to estimate the budget effect of adding omalizumab to the treatment of such patients.

\section{Methods}

\section{Study design and study population}

This study utilizes two pharmacoeconomic analyses: a costof-illness analysis and a budget-effect analysis. Data were obtained retrospectively from medical records of patients with refractory CSU who did not respond to the maximum standard therapy and received omalizumab. All patients were followed at the Al-Rashed Allergy Center in Kuwait.

The inclusion criteria were as follows: Kuwaiti patients older than 15 years with a diagnosis of CSU who failed to respond to maximum conventional medical therapy (up to fourfold of second-generation $\mathrm{H} 1$-antihistamines) and received omalizumab therapy for at least 1 year. The exclusion criteria were pregnancy and patients with CSU who had received omalizumab for $<1$ year.
The following data were obtained from patient databases in 2014: demographic information, history of CSU, onset, severity of the disease, presence of angioedema, number of exacerbations of urticaria and angioedema over the past year, physician visits, hospital admissions and emergency room (ER) visits, and medications used. These data were collected for the year prior to starting omalizumab therapy and for the year during therapy.

\section{Prevalence estimation}

There is lack of data related to the prevalence of CU, particularly CSU, in Kuwait. Hence, we used the Delphi method ${ }^{20,21}$ to estimate the prevalence of refractory CSU in Kuwait. A panel of ten allergists was asked three questions: "What do you think is the prevalence of CU in Kuwait?"; "What do you think is the prevalence of CSU in Kuwait?"; and "What do you think is the prevalence of patients with refractory CSU?" The average of the responses was taken and presented in the second round. Then, the average of the second round was taken. The obtained figure was used to indicate the local prevalence of refractory CSU.

\section{Identification and allocation of costs}

In Kuwait, the Ministry of Health (MOH) regulates the basic pricing of health services for both the public and the private sectors. The Kuwaiti government offers all medical services and medications for free to citizens and charges minimally for expatriates.

Information on the costs of drugs was obtained from the Central Medical Stores in the MOH. The outpatient visit cost was estimated from personal communication with allergists working in the $\mathrm{MOH}$ regarding their salaries and their costs of treating a patient with CSU. The cost of ER visits was taken from a study ${ }^{22}$ conducted in Kuwait on patients with bronchial asthma. We studied the burden on the health care system and not the society as a whole.

We tried to estimate, as closely as possible, the real expenditure for the treatment of refractory CSU from the health care perspective. Costs are reported in US dollars (USD) based on 2014 tariffs. No discounting was applicable.

\section{Sensitivity analysis}

A one-way sensitivity analysis was conducted on the prices and utilization of each cost component by varying its value by $\pm 25 \%$. In addition, a break-even price was calculated to determine how much the price of omalizumab would have to be reduced so that treating CSU with omalizumab would have the same cost as treating it without omalizumab. 


\section{Ethics}

The Research Ethics Committee at the Faculty of Medicine and the $\mathrm{MOH}$ approved the protocol for the study (number 2015/201). All patients provided written informed consent before participating in the study.

\section{Results}

\section{Study population and prevalence}

The results of the Delphi method indicated that the prevalence of CU in the population of Kuwait was $2 \%$, the prevalence of CSU among the CU cases was $80 \%$, and the prevalence of refractory CSU was $10 \%$ among all CSU cases.

According to the 2014 local Kuwait Population Census, the total Kuwaiti population comprises 1,275,857 individuals. Of these individuals, 467,249 are between 0 year and 14 years of age, which leaves a total of 808,608 Kuwaiti adults.
The estimated number of patients with $\mathrm{CU}$ in Kuwait is $808,608 \times 2 \%=16,172$; the estimated number of patients with CSU in Kuwait is $16,172 \times 80 \%=12,937$; and the estimated number of patients with refractory CSU in Kuwait is $12,937 \times 10 \%=1,293$ patients. The last number was used in all subsequent calculations.

\section{Direct medical costs}

The direct medical costs considered in this study included the cost of diagnostics, the cost of drugs, the cost of outpatient visits, and the cost of ER visits. A summary of all direct costs and cost calculations is presented in Table 1. All costs are annual costs.

\section{Cost of diagnostics}

Diagnostic tests were conducted for all patients with CSU regardless of their response to medical therapy. The blood

Table I Cost analysis

\begin{tabular}{|c|c|c|c|c|c|c|c|}
\hline \multirow[t]{2}{*}{ Item } & \multicolumn{3}{|c|}{ Before use of omalizumab } & \multicolumn{3}{|c|}{ After use of omalizumab } & \multirow{2}{*}{$\begin{array}{l}\text { Budget } \\
\text { impact }\end{array}$} \\
\hline & $\begin{array}{l}\text { Number } \\
\text { of units }\end{array}$ & $\begin{array}{l}\text { Unit cost, } \\
\text { USD }\end{array}$ & $\begin{array}{l}\text { Total cost, } \\
\text { USD }\end{array}$ & $\begin{array}{l}\text { Number } \\
\text { of units }\end{array}$ & $\begin{array}{l}\text { Unit cost, } \\
\text { USD }\end{array}$ & $\begin{array}{l}\text { Cost of adding } \\
\text { omalizumab, USD }\end{array}$ & \\
\hline \multicolumn{8}{|l|}{ Diagnostics } \\
\hline ANA & 1,293 & 1.32 & I,707 & 1,293 & 1.32 & $\mathrm{I}, 707$ & \\
\hline $\mathrm{TSH}$ & 1,293 & 3.3 & 4,267 & 1,293 & 3.3 & 4,267 & \\
\hline FT4 & I,293 & 1.32 & I,707 & I,293 & 1.32 & I,707 & \\
\hline Total IgE & I,293 & 1.32 & I,707 & I,293 & 1.32 & $\mathrm{I}, 707$ & \\
\hline Anti-TPO & I,293 & 9.9 & $|2,80|$ & I,293 & 9.9 & $|2,80|$ & \\
\hline ATA & 1,293 & 53.42 & 69,072 & 1,293 & 53.42 & 69,072 & \\
\hline Anti-ENA & 1,293 & 9.9 & $|2,80|$ & $\mathrm{I}, 293$ & 9.9 & $|2,80|$ & \\
\hline Total cost & & & 104,062 & & & 104,062 & 0 \\
\hline \multicolumn{8}{|l|}{ Conventional drug therapy } \\
\hline $\mathrm{NSA}^{\mathrm{a}}$ & $1,887,780$ & 0.12 & 226,534 & 250,755 & 0.12 & 30,091 & $-196,443$ \\
\hline Montelukast ${ }^{\mathrm{b}}$ & 409,176 & 0.10 & 40,918 & 0 & 0.10 & 0 & $-40,918$ \\
\hline Ranitidine ${ }^{c}$ & 943,890 & 0.01 & 9,439 & 0 & 0.01 & 0 & $-9,439$ \\
\hline Steroids ${ }^{d}$ & 354,760 & 0.02 & 7,095 & 8,600 & 0.02 & 172 & $-6,923$ \\
\hline Total cost & & & 283,986 & & & 30,263 & $-253,723$ \\
\hline Omalizumab & & & & 31,032 & 495.21 & $15,367,357$ & $15,367,357$ \\
\hline \multicolumn{8}{|l|}{ Outpatient visit } \\
\hline Urticaria exacerbations $^{\mathrm{e}}$ & 77,400 & 37.97 & $2,938,878$ & 8,280 & 37.97 & 314,392 & $-2,624,486$ \\
\hline \multirow[t]{2}{*}{ Angioedema exacerbations $^{f}$} & $\mathrm{I}, 792$ & 37.97 & 68,042 & 129 & 37.97 & 4,898 & $-63, \mid 44$ \\
\hline & & & $3,006,920$ & & & 319,290 & $-2,687,630$ \\
\hline Angioedema ER visits ${ }^{g}$ & $\mathrm{I}, 406$ & 181.91 & 255,765 & 42 & 181.91 & 7,640 & $-248,125$ \\
\hline Total cost & & & $3,650,733$ & & & $|5,828,6| 2$ & $+12,177,879$ \\
\hline \multirow{9}{*}{\multicolumn{8}{|c|}{ 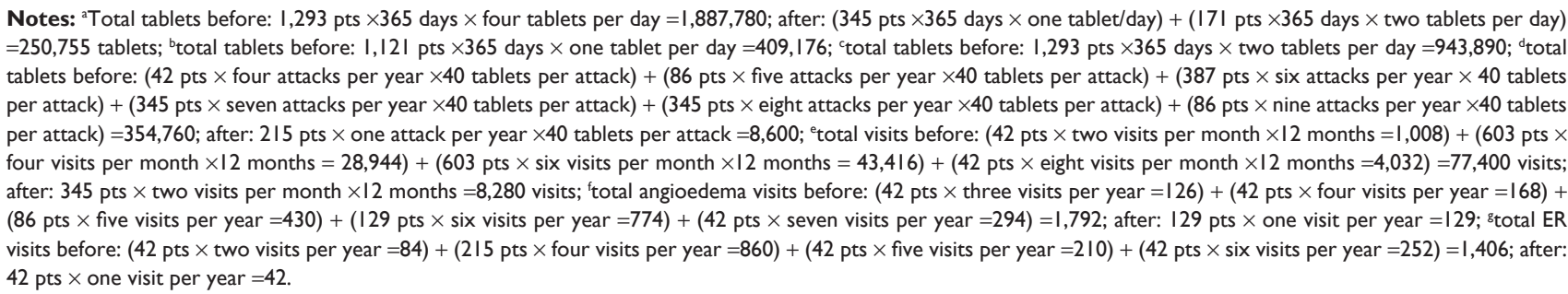 }} \\
\hline & & & & & & & \\
\hline & & & & & & & \\
\hline & & & & & & & \\
\hline & & & & & & & \\
\hline & & & & & & & \\
\hline & & & & & & & \\
\hline & & & & & & & \\
\hline & & & & & & & \\
\hline \multicolumn{8}{|c|}{$\begin{array}{l}\text { Abbreviations: USD, US dollars; ANA, antinuclear antibody; TSH, thyroid stimulating hormone; FT4, free thyroxine; IgE, immunoglobulin E; TPO, thyroid peroxidase; ATA, } \\
\text { anti-thyroglobulin antibody; ENA, extractable nuclear antigen; ER, emergency room; NSA, sedating antihistamine; pts, patients. }\end{array}$} \\
\hline
\end{tabular}


investigations were conducted once during the patient's clinical course, preferably at an earlier clinic visit. These tests included estimation of antinuclear antibody (ANA), thyroid stimulating hormone (TSH), free thyroxine (FT4), total IgE, anti-thyroid peroxidase (anti-TPO) antibody, antithyroglobulin antibody (ATA), and anti-extractable nuclear antigens (anti-ENA) antibodies. The cost figures for these tests were provided by the MOH. The total cost of all diagnostics is shown in Table 1.

\section{Cost of drugs}

Before use of omalizumab, all patients were receiving the maximum recommended doses of second-generation H1-antihistamines (up to fourfold a day). The top three nonsedating antihistamines used by the patients were levocetirizine, desloratadine, and cetirizine. After using omalizumab, up to $60 \%$ of the patients were not taking any antihistamines (Table 1).

Montelukast is a leukotriene receptor antagonist that was used as an add-on therapy for patients with refractory CSU. A single daily dose of a $10 \mathrm{mg}$ tablet was used by $86.7 \%$ of patients before they used omalizumab. After using omalizumab, all patients stopped using montelukast (Table 1).

Ranitidine is an H2-antihistamine that was used by all refractory CSU cases at a dosage of two $150 \mathrm{mg}$ tablets per day. After using omalizumab, all patients stopped using ranitidine (Table 1).

Short courses of systemic steroids were used during exacerbations when patients were refractory to the use of second-generation H1-antihistamines (up to fourfold a day). During the year prior to omalizumab use, short courses of steroids were used for exacerbations at a frequency of four to nine attacks per year. However, after omalizumab use, the majority of patients (83.3\%) had no attacks, and $16.7 \%$ of patients had only one attack per year (Table 1).

All refractory CSU cases received omalizumab for at least 1 year after failing to respond to maximum medical therapy. The dosage of omalizumab was two vials per month for 1 year (each vial is $150 \mathrm{mg}$ ).

\section{Cost of outpatient visits}

Approximately half of the patients (46.7\%) had at least six visits per month for 1 year. An outpatient visit for disease exacerbation took $\sim 30$ minutes, with a cost of USD 37.95 (because 1 hour of physician time at the clinic costs USD 75.90). After the use of omalizumab, two-thirds of patients had no more exacerbations and showed a significant reduction in the total cost of outpatient visits (Table 1).
Almost $26.7 \%$ of our patients had angioedema. The outpatient visits related to angioedema attacks had the same costs as a normal exacerbation visit. After the use of omalizumab, the number of visits was reduced; $\sim 10 \%$ of the patients had one outpatient visit per year, and $16.7 \%$ had no visits (Table 1).

\section{Cost of ER visits}

Some refractory cases of CSU with angioedema went to the ER, which was probably more accessible than the outpatient clinic, particularly on weekends. Approximately 20\% of patients had four to five ER visits per year. After the use of omalizumab, one-quarter of patients had no more exacerbations, and the remainder had only one ER visit (Table 1).

\section{Total CSU costs}

The total cost for treatment of patients with refractory CSU before and after using omalizumab is shown in Table 1. The budget impact of switching to omalizumab was an extra amount of USD $12,177,879$ per year, which is USD 9,418 extra per patient, per year.

\section{Sensitivity analyses}

The results of the sensitivity analyses are shown in Table 2. The variables with the greatest effect on the costs of treating CSU before omalizumab were the price and utilization of outpatient visits. The variable with the greatest effect on the costs of treating CSU after omalizumab was the price of omalizumab. The break-even analysis indicated that the price of omalizumab would have to fall to USD 102.3 per vial, from the current level of USD 495 per vial, for treatment with omalizumab to be equal to the costs of treating CSU without omalizumab.

Table 2 One-way sensitivity analysis: effect of varying the price of each cost component by $\pm 25 \%$ on total costs of treating CSU

\begin{tabular}{|c|c|c|c|c|}
\hline \multirow[t]{3}{*}{ Cost component } & \multicolumn{4}{|c|}{ \pm Change in total treatment costs, USD } \\
\hline & \multicolumn{2}{|c|}{$\begin{array}{l} \pm 25 \% \text { change in } \\
\text { price }\end{array}$} & \multicolumn{2}{|c|}{$\begin{array}{l} \pm 25 \% \text { change in } \\
\text { utilization }\end{array}$} \\
\hline & Before & After & Before & After \\
\hline Omalizumab & $N A^{a}$ & $3,840,210$ & $N A^{a}$ & $N A^{b}$ \\
\hline Outpatient visits & 751,334 & 79,781 & 751,334 & 79,781 \\
\hline Conventional drugs & 69,845 & 7,491 & 12,220 & 7,491 \\
\hline ER visits & 63,914 & ।,91। & 63,914 & 1,911 \\
\hline Diagnostic tests & 26,007 & 26,007 & $N A^{b}$ & $N A^{b}$ \\
\hline
\end{tabular}

Notes: "Omalizumab was not used in the "Before" period. ${ }^{\mathrm{b}} \mathrm{All}$ patients were given diagnostic testing and, in the "After" period, omalizumab; so it was not relevant to vary utilization of these factors.

Abbreviations: CSU, chronic spontaneous urticaria; USD, US dollars; ER, emergency room; NA, not applicable. 


\section{Discussion}

This study documented the direct medical costs of refractory CSU treatment in Kuwait. To the best of our knowledge, this study is the first to evaluate the economic burden of refractory CSU in a Middle Eastern country. The economic burden and cost of treatment for refractory CSU is substantial. The estimated total direct medical cost of treatment for refractory CSU before the use of omalizumab was $\sim$ USD 3,650,733 per year, which is USD 2,823 per patient, per year. The estimated total medical cost of treatment for refractory CSU after the use of omalizumab, a new FDA-approved monoclonal antiIgE antibody for CSU, was USD $15,828,612$, which is USD 12,242 per patient, per year. This finding indicates that the budget effect of switching to omalizumab is an extra amount of USD $12,177,879$ per year, which is USD 9,418 extra per patient, per year.

Hay et $\mathrm{a}^{23}$ estimated the global burden of disease attributable to 15 categories of skin disease from 1990 to 2010 for 187 countries. They found that urticaria was among the top ten most prevalent diseases worldwide in $2010{ }^{23}$

Using the Delphi method, we found that the prevalence of $\mathrm{CU}$ in Kuwait is $2 \%$ of the population, the prevalence of $\mathrm{CSU}$ is $\sim 80 \%$ of $\mathrm{CU}$ cases, and the prevalence of refractory $\mathrm{CSU}$ is $\sim 10 \%$ of all CSU cases. Although CU is considered one of the diseases that most frequently lead to consultations with general practitioners, pediatricians, dermatologists, allergists, and other health doctors, there is lack of published data investigating the prevalence of urticaria in the population. The lifetime prevalence rate of urticaria in the German population is estimated to be $8.8 \%-10 \%$ (confidence interval $[95 \% \mathrm{CI}]$ : $7.9 \%-9.7 \%$ ) for all types of urticaria and $9 \%$ for the Norwegian population. However, it was $1.8 \%$ (95\% CI: $1.4 \%-2.3 \%$ ) only for $\mathrm{CU}$ in the German population, and it was $0.6 \%(95 \% \mathrm{CI}$ : $0.4 \%-0.8 \%$ ) for CU in the Spanish population. ${ }^{9,24,25}$ Our figures are consistent with these published data.

Direct medical costs considered in this study included the cost of diagnostics, the cost of drugs, the cost of outpatient visits, and the cost of ER visits. The leading contributor to direct medical costs is the use of omalizumab for treatment. The variables with the strongest effect on the costs of treating CSU before omalizumab administration are the price and number of outpatient visits. Patients with CSU are seen frequently at outpatient clinics or in the ER during their exacerbations of urticaria and angioedema. In our study, approximately half of the patients $(46.7 \%)$ had at least six visits per month for 1 year for their urticaria exacerbations (total of 77,400 urticaria visits and 1,792 angioedema visits per year), and the total cost of outpatient visits was USD
3,006,920. Angioedema can be associated with CSU urticaria in $\sim 33 \%-67 \%$ of all patients with CSU., ${ }^{9,26}$ Angioedema was present in $26.7 \%$ of our patients with CSU. The total cost for outpatient visits was USD 68,042, and the total cost of angioedema ER visits was USD 255,765.

Delong et $\mathrm{al}^{27}$ evaluated the direct and indirect health care costs of patients with CIU from allergy and dermatology ambulatory clinics at The Johns Hopkins University from a societal perspective using a survey-guided and retrospective medical record review. They estimated the direct health care costs, which included laboratory, medication, outpatient visit, and emergency department and hospital visit costs, and the indirect costs, which included earnings lost due to traveling to outpatient visits and absences from work due to CIUrelated illness. They found that patients with CSU consumed a mean standard deviation $( \pm \mathrm{SD})$ of USD 2,047 ( \pm USD 1,483) annually. Because CSU is primarily an outpatient disease, medication costs alone accounted for $62.5 \%$ (USD 1,280) of the total annual cost. Our results are in accordance with those of Delong et al. ${ }^{27}$

The direct costs of outpatient and ER visits for urticaria and angioedema attacks were $\sim$ USD 3,262,685 - the highest cost variable in our study - before using omalizumab. The medication cost before omalizumab use was the second highest in this study, with a total cost of USD 283,986.

However, after use of omalizumab in patients who did not improve through maximum medical therapy, the variable with the most effect on the CSU costs was the price of omalizumab itself. A total of USD 15,828,612 was the estimated cost of treating patients with refractory CSU using omalizumab, with a budget effect of an extra amount of USD $12,177,879$ per year.

The break-even analysis indicated that the price of omalizumab would have to fall to USD 102.3 per vial, from the current level of USD 495 per vial, for treatment with omalizumab to be equal to the costs of treating CSU without omalizumab. This decrease would represent a substantial discount from the drug's current cost.

All budget-effect studies related to use of omalizumab are associated with its use in airway allergies, particularly in bronchial asthma. Omalizumab was approved for use in moderate-to-severe persistent allergic asthma in 2006, and the cost-effectiveness data showed that omalizumab is indeed cost effective in improving patients' clinical outcome and health-related QoL. ${ }^{28-30}$

Our study has a number of limitations. In particular, only direct medical costs were measured. Direct nonmedical costs, such as transport to hospitals, indirect costs resulting 
from days lost from work and school, and intangible costs resulting from changes in QoL and social consequences are likely to result in an even greater total cost burden of CSU. Furthermore, our prevalence estimates were based on expert opinion. The use of the Delphi Method may have improved these estimates, but the estimates were still based on expert opinion rather than actual measurement in the population.

To our knowledge, this is the first study to describe the economic burden and cost analysis of patients with CSU before and after the use of omalizumab. This study revealed that the annual direct cost of CSU is substantial. The leading contributors to the annual cost among all patients with CSU before omalizumab use are the price and utilization of outpatient visits. However, after the use of omalizumab, the leading contributor to the cost is omalizumab. Although the use of omalizumab increases drug costs, it results in lower outpatient clinic and ER costs because it treats patients more effectively. Because omalizumab is safe, it would be more economic if it were self-administered by the patient as an offlabel option at increasing intervals every 5 weeks or 6 weeks. Future studies are needed to assess the indirect costs of CSU, the cost-effectiveness of omalizumab in this condition, and the effects of omalizumab treatment on patients' QoL.

\section{Acknowledgment}

This work has no funding source.

\section{Disclosure}

The authors report no conflicts of interest in this work.

\section{References}

1. Zuberbier T, Asero R, Bindslev-Jensen C, et al; Dermatology Section of the European Academy of Allergology and Clinical Immunology; Global Allergy and Asthma European Network; European Dermatology Forum; World Allergy Organization. EAACI/GA(2)LEN/EDF/WAO guideline: definition, classification and diagnosis of urticaria. Allergy. 2009;64(10):1417-1426.

2. Grattan CE, Sabroe RA, Greaves MW. Chronic urticaria. J Am Acad Dermatol. 2002;46(5):645-657. quiz 657-660.

3. Hide M, Francis DM, Grattan CE, Hakimi J, Kochan JP, Greaves MW. Autoantibodies against the high-affinity $\operatorname{IgE}$ receptor as a cause of histamine release in chronic urticaria. N Engl J Med. 1993;328(22): $1599-1604$

4. Altrichter S, Peter HJ, Pisarevskaja D, Metz M, Martus P, Maurer M. IgE mediated autoallergy against thyroid peroxidase - a novel pathomechanism of chronic spontaneous urticaria? PLoS One. 2011;6(4):e14794.

5. Maurer M, Altrichter S, Bieber T, et al. Efficacy and safety of omalizumab in patients with chronic urticaria who exhibit IgE against thyroperoxidase. J Allergy Clin Immunol. 2011;128(1):202-209.e205.

6. Sabroe RA, Poon E, Orchard GE, et al. Cutaneous inflammatory cell infiltrate in chronic idiopathic urticaria: comparison of patients with and without anti-FcepsilonRI or anti-IgE autoantibodies. J Allergy Clin Immunol. 1999;103(3 pt 1):484-493.
7. Maurer M, Weller K, Bindslev-Jensen C, et al. Unmet clinical needs in chronic spontaneous urticaria. A GA(2)LEN task force report. Allergy. 2011;66(3):317-330.

8. Kang MJ, Kim HS, Kim HO, ParkYM. The impact of chronic idiopathic urticaria on quality of life in korean patients. Ann Dermatol. 2009; 21(3):226-229.

9. Zuberbier T, Balke M, Worm M, Edenharter G, Maurer M. Epidemiology of urticaria: a representative cross-sectional population survey. Clin Exp Dermatol. 2010;35(8):869-873.

10. O'Donnell BF. Urticaria: impact on quality of life and economic cost. Immunol Allergy Clin North Am. 2014;34(1):89-104.

11. Engin B, Uguz F, Yilmaz E, Ozdemir M, Mevlitoglu I. The levels of depression, anxiety and quality of life in patients with chronic idiopathic urticaria. J Eur Acad Dermatol Venereol. 2008;22(1):36-40.

12. Zuberbier T, Aberer W, Asero R, et al; European Academy of Allergy and Clinical Immunology; Global Allergy and Asthma European Network; European Dermatology Forum; World Allergy Organization. The EAACI/GA(2) LEN/EDF/WAO Guideline for the definition, classification, diagnosis, and management of urticaria: the 2013 revision and update. Allergy. 2014;69(7):868-887.

13. Wu KC, Jabbar-Lopez ZK. Omalizumab, an Anti-IgE mAb, receives approval for the treatment of chronic idiopathic/spontaneous urticaria. J Invest Dermatol. 2015;135(1):13-15.

14. Zuberbier T, Maurer M. Omalizumab for the treatment of chronic urticaria. Expert Rev Clin Immunol. 2015;11(2):171-180.

15. Saini SS, Bindslev-Jensen C, Maurer M, et al. Efficacy and safety of omalizumab in patients with chronic idiopathic/spontaneous urticaria who remain symptomatic on $\mathrm{H} 1$ antihistamines: a randomized, placebocontrolled study. J Invest Dermatol. 2015;135(3):925.

16. Vichyanond P. Omalizumab in allergic diseases, a recent review. Asian Pac J Allergy Immunol. 2011;29(3):209-219.

17. Mitchell S, Balp MM, Samuel M, McBride D, Maurer M. Systematic review of treatments for chronic spontaneous urticaria with inadequate response to licensed first-line treatments. Int J Dermatol. 2015;54(9):1088-1104.

18. McCormack PL. Omalizumab: a review of its use in patients with chronic spontaneous urticaria. Drugs. 2014;74(14):1693-1699.

19. Kaplan AP, Joseph K, Maykut RJ, Geba GP, Zeldin RK. Treatment of chronic autoimmune urticaria with omalizumab. JAllergy Clin Immunol. 2008;122(3):569-573.

20. Shawahna R, Masri D, Al-Gharabeh R, Deek R, Al-Thayba L, Halaweh M. Medication administration errors from a nursing viewpoint: a formal consensus of definition and scenarios using a Delphi technique. J Clin Nurs. 2016;25(3-4):412-423.

21. Rosengart MR, Nathens AB, Schiff MA. The identification of criteria to evaluate prehospital trauma care using the Delphi technique. JTrauma. 2007;62(3):708-713.

22. Khadadah M. The cost of asthma in Kuwait. Med Princ Pract. 2013; 22(1):87-91.

23. Hay RJ, Johns NE, Williams HC, et al. The global burden of skin disease in 2010: an analysis of the prevalence and impact of skin conditions. J Invest Dermatol. 2014;134(6):1527-1534.

24. Gaig P, Olona M, Munoz Lejarazu D, et al. Epidemiology of urticaria in Spain. J Investig Allergol Clin Immunol. 2004;14(3):214-220.

25. Bakke P, Gulsvik A, Eide GE. Hay fever, eczema and urticaria in southwest Norway. Lifetime prevalences and association with sex, age, smoking habits, occupational airborne exposures and respiratory symptoms. Allergy. 1990;45(7):515-522.

26. Kozel MM, Mekkes JR, Bossuyt PM, Bos JD. Natural course of physical and chronic urticaria and angioedema in 220 patients. $J \mathrm{Am}$ Acad Dermatol. 2001;45(3):387-391.

27. Delong LK, Culler SD, Saini SS, Beck LA, Chen SC. Annual direct and indirect health care costs of chronic idiopathic urticaria: a cost analysis of 50 nonimmunosuppressed patients. Arch Dermatol. 2008;144(1):35-39. 
28. Faria R, McKenna C, Palmer S. Optimizing the position and use of omalizumab for severe persistent allergic asthma using costeffectiveness analysis. Value Health. 2014;17(8):772-782.

29. Norman G, Faria R, Paton F, et al. Omalizumab for the treatment of severe persistent allergic asthma: a systematic review and economic evaluation. Health Technol Assess. 2013;17(52):1-342.
30. Dal Negro RW, Pradelli L, Tognella S, Micheletto C, Iannazzo S. Cost-utility of add-on omalizumab in difficult-to-treat allergic asthma in Italy. Eur Ann Allergy Clin Immunol. 2011;43(2):45-53.

\section{Publish your work in this journal}

ClinicoEconomics \& Outcomes Research is an international, peerreviewed open-access journal focusing on Health Technology Assessment, Pharmacoeconomics and Outcomes Research in the areas of diagnosis, medical devices, and clinical, surgical and pharmacological intervention. The economic impact of health policy and health systems organization also constitute important areas of coverage. The manuscript management system is completely online and includes a very quick and fair peer-review system, which is all easy to use. Visit http://www.dovepress.com/testimonials.php to read real quotes from published authors.

Submit your manuscript here: http://www.dovepress.com/clinicoeconomics-and-outcomes-research-journal 